\title{
Effect of HIPing on conductivity and impedance measurements of $\mathrm{DyBi}_{5} \mathrm{Fe}_{2} \mathrm{Ti}_{3} \mathrm{O}_{18}$ ceramics
}

\author{
N V PRASAD, G PRASAD, MAHENDRA KUMAR ${ }^{\dagger}$, S V SURYANARAYANA, \\ T BHIMASANKARAM and G S KUMAR* \\ Department of Physics, Osmania University, Hyderabad 500 007, India \\ †Defence Metallurgical Research Laboratory, Hyderabad 500 058, India
}

MS received 9 May 2000; revised 14 September 2000

\begin{abstract}
X-ray diffraction, a.c. impedance and conductivity (a.c. and d.c.) have been used to characterize $\mathrm{DyBi}_{5} \mathrm{Fe}_{2} \mathrm{Ti}_{3} \mathrm{O}_{18}$. Samples were prepared by solid state double sintering method. A few samples were also subjected to hot isostatic pressing (HIP) at $800^{\circ} \mathrm{C}$ for $2 \mathrm{~h}$ at $100 \mathrm{MPa}$ pressure. The data on XRD, impedance and conductivity of two sets of samples are compared to understand study of effect of HIPing on the properties of $\mathrm{DyBi}_{5} \mathrm{Fe}_{2} \mathrm{Ti}_{3} \mathrm{O}_{18}$.
\end{abstract}

Keywords. Hot isostatic pressing (HIP); bismuth layered structure ferroelectrics (BLSF); ferroelectromagnetic materials; relaxor ferroelectrics.

\section{Introduction}

Bismuth layered structure ferroelectrics (BLSF) have received an increasing interest as high temperature piezo and pyroelectric materials since they possess high Curie temperature, anisotropic characteristics and many other interesting properties for possible device applications (Subba Rao 1962; Takenaka and Sakata 1980; Fregoso 1997). The BLSF compounds crystallize in the orthorhombic structure and are characterized by $\left(\mathrm{Bi}_{2} \mathrm{O}_{2}\right)^{2+}$ sheets interleaved with perovskite layers of $\left(\mathrm{A}_{n-1} \mathrm{~B}_{n} \mathrm{O}_{3 n+1}\right)^{2-}$ (Aurivillius 1949, 1950). For example, $\mathrm{Bi}_{4} \mathrm{Ti}_{3} \mathrm{O}_{12}$ can be represented as $\left(\mathrm{Bi}_{2} \mathrm{O}_{2}\right)^{2+}\left(\mathrm{Bi}_{2} \mathrm{Ti}_{3} \mathrm{O}_{10}\right)^{2-}\left(\mathrm{A}=\mathrm{Bi}^{3+}, \mathrm{B}=\mathrm{Ti}^{4+}\right.$ and $n=3$ ). In the above formula $n$ is the number of perovskite layers in the compound. A number of compounds with the substitution of $\mathrm{Bi}^{3+}$ with rare earths and $\mathrm{B}=\mathrm{Fe}^{3+} / \mathrm{Ti}^{4+}$ have been reported (Ismailzade 1967; Suryanarayana 1994; Singh 1996; James et al 1998; Srinivas and James 1999). In addition, the results on impedance characteristics on $\mathrm{LaBi}_{4} \mathrm{FeTi}_{3} \mathrm{O}_{15}$ were also reported on the samples prepared both by uniaxial and cold isostatic pressing (James et al 1998).

In our earlier paper (Prasad et al 1998), results on $\mathrm{SmBi}_{5} \mathrm{Fe}_{2} \mathrm{Ti}_{3} \mathrm{O}_{18}$, which can be represented as $\left(\mathrm{SmBi}_{3} \mathrm{Ti}_{3} \mathrm{O}_{12}\right)$ $+2\left(\mathrm{BiFeO}_{3}\right)$ or $\left(\mathrm{Bi}_{4} \mathrm{Ti}_{3} \mathrm{O}_{12}\right)+\mathrm{BiFeO}_{3}+\mathrm{SmFeO}_{3}$ have been reported. The present compound $\mathrm{DyBi}_{5} \mathrm{Fe}_{2} \mathrm{Ti}_{3} \mathrm{O}_{18}$ is analogous to the above compound. All these compounds are known to exhibit simultaneous ferroelectric and magnetic ordering. The rare earth ortho ferrite $\left(\mathrm{SmFeO}_{3}\right.$ or

\footnotetext{
*Author for correspondence
}

$\mathrm{DyFeO}_{3}$ ) have perovskite structure and belongs to a family of antiferromagnetics with unusual magnetic properties (White 1969; Gabbasova et al 1991). Gabbasova et al (1991) reported that substitution of $\mathrm{Dy}^{3+}$ for $\mathrm{Bi}^{3+}$ in small quantities showed higher magnetoelectric output. This prompted the authors to look into the effect of rare earth ions substituted for bismuth in the parent compound $\mathrm{Bi}_{6} \mathrm{Fe}_{2} \mathrm{Ti}_{3} \mathrm{O}_{18}$ (Prasad and Kumar 2000). While high Curie temperature in some of these compounds is an attraction for high temperature applications, there is a difficulty, since the materials do not have large remanance either in piezoelectric or piezomagnetic polarizations at a level desirable for device applications. Hence new and improved methods of processing these ceramics may result in improved material characteristics. Piezoelectric and piezomagnetic properties are essentially dependent upon electromechanical and magnetomechanical coupling respectively and these energy conversions are intimately connected with grain size and grain orientations. Hot isostatic pressing (HIP) offers the advantage of rapid densification by minimizing the time for grain growth resulting in a finer and more uniform microstructure.

The aim of the present paper is to compare the results on $\mathrm{DyBi}_{5} \mathrm{Fe}_{2} \mathrm{Ti}_{3} \mathrm{O}_{18}$ prepared by two processes: ceramics prepared by solid state sintering and those subjected to HIPing.

\section{Experimental}

The polycrystalline materials of $\mathrm{DyBi}_{5} \mathrm{Fe}_{2} \mathrm{Ti}_{3} \mathrm{O}_{18}$ were prepared by double sintering through solid state reaction 
method. Stoichiometric amounts of AR grade $\mathrm{Bi}_{2} \mathrm{O}_{2}$, $\mathrm{Ti}_{2} \mathrm{O}_{2}, \mathrm{Fe}_{2} \mathrm{O}_{3}$ and $\mathrm{Dy}_{2} \mathrm{O}_{3}$ were taken and thoroughly mixed and calcined at $850^{\circ} \mathrm{C}$ for $2 \mathrm{~h}$. Pellets were obtained by uniaxially pressing the presintered powder at $8 \mathrm{MPa}$. Requisite amount of binder (polyvinyl alcohol) was added before pressing the powder. The samples were sintered at $900^{\circ} \mathrm{C}$ for $4 \mathrm{~h}$ and allowed to cool (sample A). One of the sintered pellets was subjected to hot isostatic pressing (HIP) at $100 \mathrm{MPa}$ for $2 \mathrm{~h}$ at $800^{\circ} \mathrm{C}$ (sample B). The samples (A and $\mathrm{B}$ ) were characterized by $\mathrm{X}$-ray diffraction to confirm the formation of single phase. X-ray data was recorded with $\mathrm{CuK}_{\alpha}$ radiation.

Impedance and conductivity measurements were carried out on both these samples using HP4192A impedance analyzer in a two-terminal sample holder in the frequency range $1 \mathrm{kHz}-1 \mathrm{MHz}$ and temperature region $30-500^{\circ} \mathrm{C}$. D.c. conductivity measurements were made using a conventional setup. Large area faces of the samples painted with silver paint served as electrodes.

\section{Results and discussion}

X-ray diffractograms of both the samples (A and B) of $\mathrm{DyBi}_{5} \mathrm{Fe}_{2} \mathrm{Ti}_{3} \mathrm{O}_{18}$ (DBFT) are shown in figures $1 \mathrm{a}$ and $\mathrm{b}$, respectively. The diffractograms are indexed and the lattice parameters are given in table 1 . The results are compared with the $\mathrm{Bi}_{6} \mathrm{Fe}_{2} \mathrm{Ti}_{3} \mathrm{O}_{18}$ (BFT). The present compounds are of pseudo orthorhombic structure with slight distortion (as indicated by b/a ratio, which is very close to unity).

SEM photographs of both sintered and HIPed DBFT samples (A and B) are shown in figures 2a and b. From the photographs it is observed that, the grain sizes in samples $A$ and $B$ are in the range of $1-2 \mu \mathrm{m}$ and $1-3 \mu \mathrm{m}$ respectively. Sample B possesses plate-like structure. The clusters of small grains seen in sample $A$ are found to disappear in sample B, where the grains are well defined and possess plate-like structure. The porosity is also found to decrease in sample B.

Figures $3 \mathrm{a}$ and $\mathrm{b}$ and $4 \mathrm{a}$ and $\mathrm{b}$ present the variation of imaginary part of impedance as a function of frequency at different temperatures for A and B samples. In sample A,

Table 1. Structural properties of BFT and DBFT samples.

\begin{tabular}{|c|c|c|}
\hline Property & BFT & DBFT \\
\hline Lattice parameter $(\AA)$ & $\begin{array}{l}a=5 \cdot 49 \\
b=5 \cdot 50 \\
c=50 \cdot 18\end{array}$ & $\begin{aligned} a & =5 \cdot 51 \\
b & =5 \cdot 48 \\
c & =49 \cdot 74\end{aligned}$ \\
\hline $\begin{array}{l}\text { Cell volume }\left(\AA^{3}\right) \\
b / a \text { ratio }\end{array}$ & $\begin{array}{l}1515 \\
1 \cdot 006\end{array}$ & $\begin{array}{l}1501 \\
0 \cdot 99\end{array}$ \\
\hline $\begin{array}{l}\text { Density }\left(\mathrm{g} / \mathrm{cm}^{3}\right) \\
\text { X-ray } \\
\text { Experimental }\end{array}$ & $\begin{array}{l}7.94 \\
7 \cdot 54\end{array}$ & $\begin{array}{l}7 \cdot 74(\text { samples A \& B }) \\
7 \cdot 12(\text { sample A }) \\
7 \cdot 50(\text { sample B })\end{array}$ \\
\hline
\end{tabular}

$Z^{\prime \prime}$ increases with the increase of frequency showing a broad peak around $500 \mathrm{kHz}$. This peak shifts to higher frequencies as the temperature is increased going beyond the range of present measurement. At all the frequencies $Z^{\prime \prime}$ values of sample A decrease with increasing temperature.

The $Z^{\prime \prime}$ values of sample B are smaller than those of sample $A$ at all temperatures and in the frequency range studied. Sample B also shows very broad peaks in the $Z^{\prime \prime}$ versus frequency curves. But the peak frequencies of these samples are much lower than those observed for sample A. These peaks also shift to higher frequencies with increase of temperature.

Figure 5a shows imaginary part of impedance $Z^{\prime \prime}$ as a function of the real part of impedance $Z^{\prime}$ at different temperatures for sample A. These curves can be resolved into
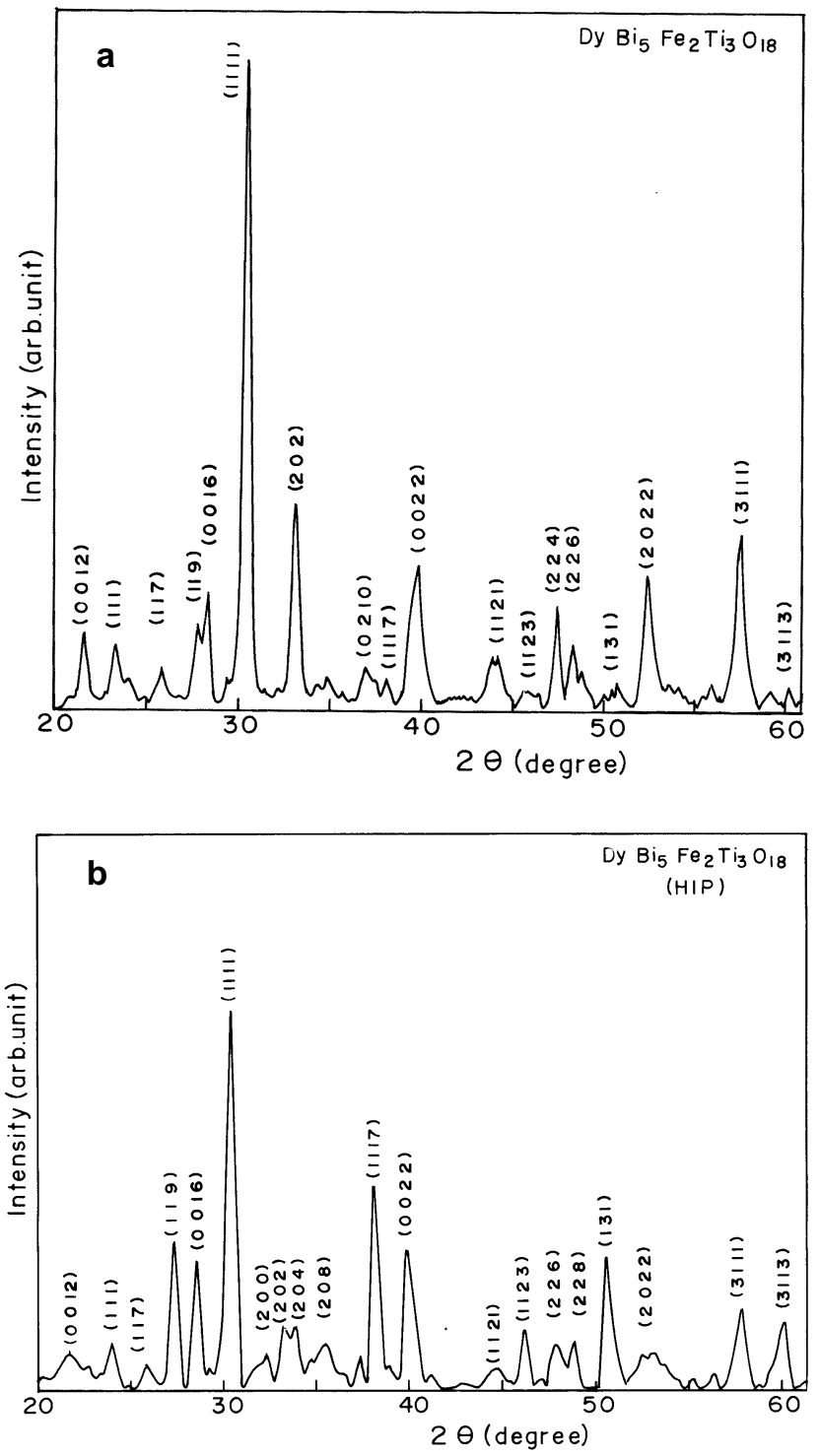

Figure 1. a. X-ray diffractogram of sintered DBFT (sample A) and b. X-ray diffractogram of sintered plus HIPed DBFT (sample B). 
two semicircles with their centres slightly depressed below the $Z^{\prime}$ axis. Figure $5 b$ gives similar data for sample B.

Figures 6 and 7 present the d.c. and a.c. conductivity for samples A and B respectively as a function of inverse temperature on semilog scale.

Hot forging is known to produce grain orientation in samples (Macdonald 1987). HIP, depending on the dimensions of the samples (suitable thickness to diameter ratio) may aid grain orientation. In the present samples XRD shows decrease in the intensity of $(00 l)$ reflections in sample B compared to sample A and a slight increase in intensity in the $(h k l)$ peaks with all odd values of $h, k$ and $l$. The X-ray density of sample B is $96 \%$ of theoretical density, while that of sample A is $91 \%$. Hence in HIPed DBFT sample better densification and grain orientation is achieved. Pertinent data on structural properties of the present compound is summarized in table 1 .

The impedance spectroscopy and dielectric properties of a substance form basis for most analysis of experimental data in the presence of microscopic charged inhomogeneities. Impedance is characterized by different
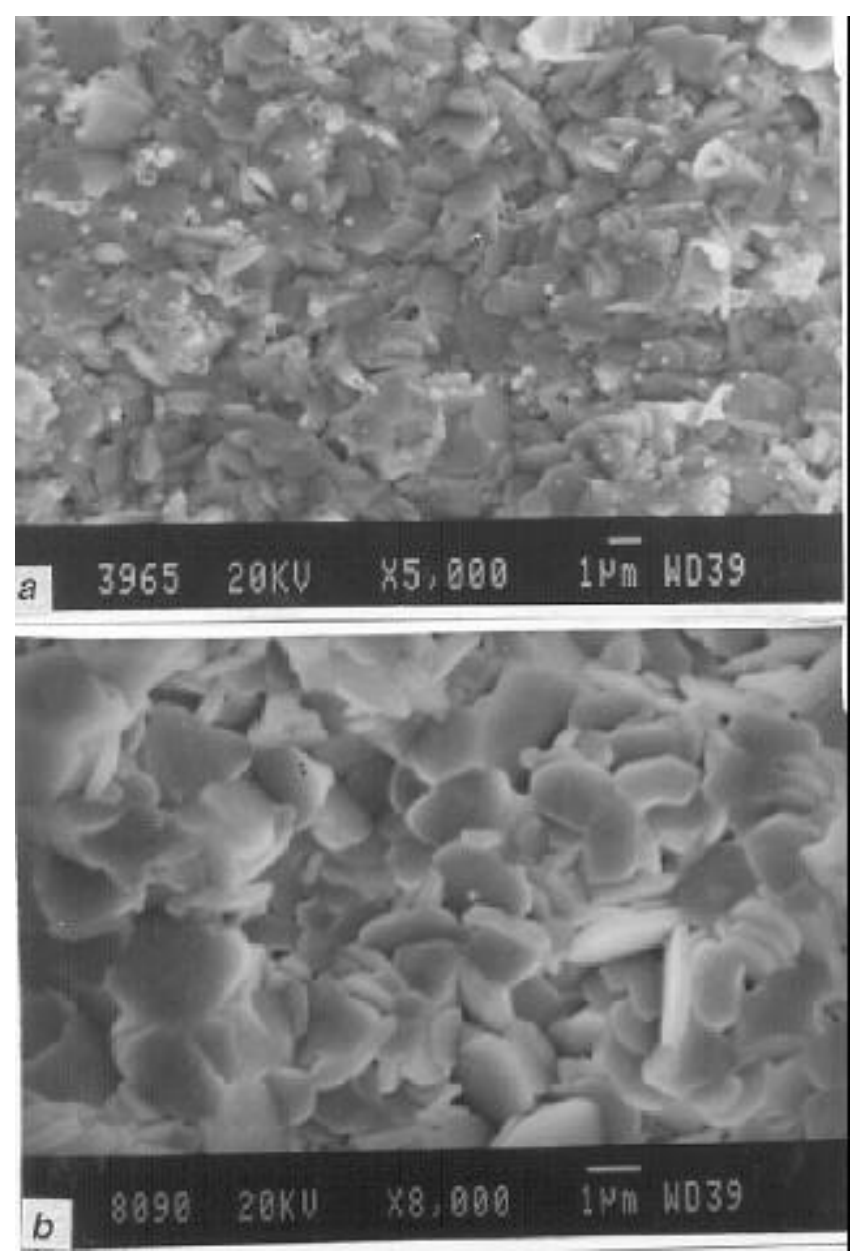

Figure 2. a-b. SEM photographs of sintered DBFT (sample A) and sintered plus HIPed DBFT (sample B). contributions from bulk conduction, grain boundary effects and interfacial phenomenon.

Variation of $Z^{\prime \prime}$ with frequency at different temperatures (figures $3 \mathrm{a}$ and $\mathrm{b}$ ) resemble characteristics of a relaxor ferroelectric. In the structure, the heterovalent ions $\left(\mathrm{Dy}^{3+}\right.$ at $\mathrm{Bi}^{3+}$ site and $\mathrm{Fe}^{3+}$ in $\mathrm{Ti}^{4+}$ position) are randomly distributed on the cation sites in the unit cell and perovskite layers. Due to slow diffusion of ions in the thermochemical process responsible for solid state sintering of the constituent oxides, there is a possibility for micro heterogeneity in the end products. Presence of different kinds of ions in the $\mathrm{A}$ and $\mathrm{B}$ sites of $\mathrm{ABO}_{3}$ lattice may result in localized lattice distortion.

The present compound consists of five units of $\mathrm{ABO}_{3}$ layers. Each of these units is separated by $\left(\mathrm{Bi}_{2} \mathrm{O}_{2}\right)^{2+}$ layers. Because of the random occupation of equivalent sites by different heterovalent ions, there can be fluctuations in the structure giving rise to disorder, which may influence the physical behaviour under the action of temperature, pressure, electric field or magnetic field. The other aspect is the varying relaxation times. The overall effect of these results in broad peak in $Z^{\prime \prime}$ versus frequency plots. HIPed
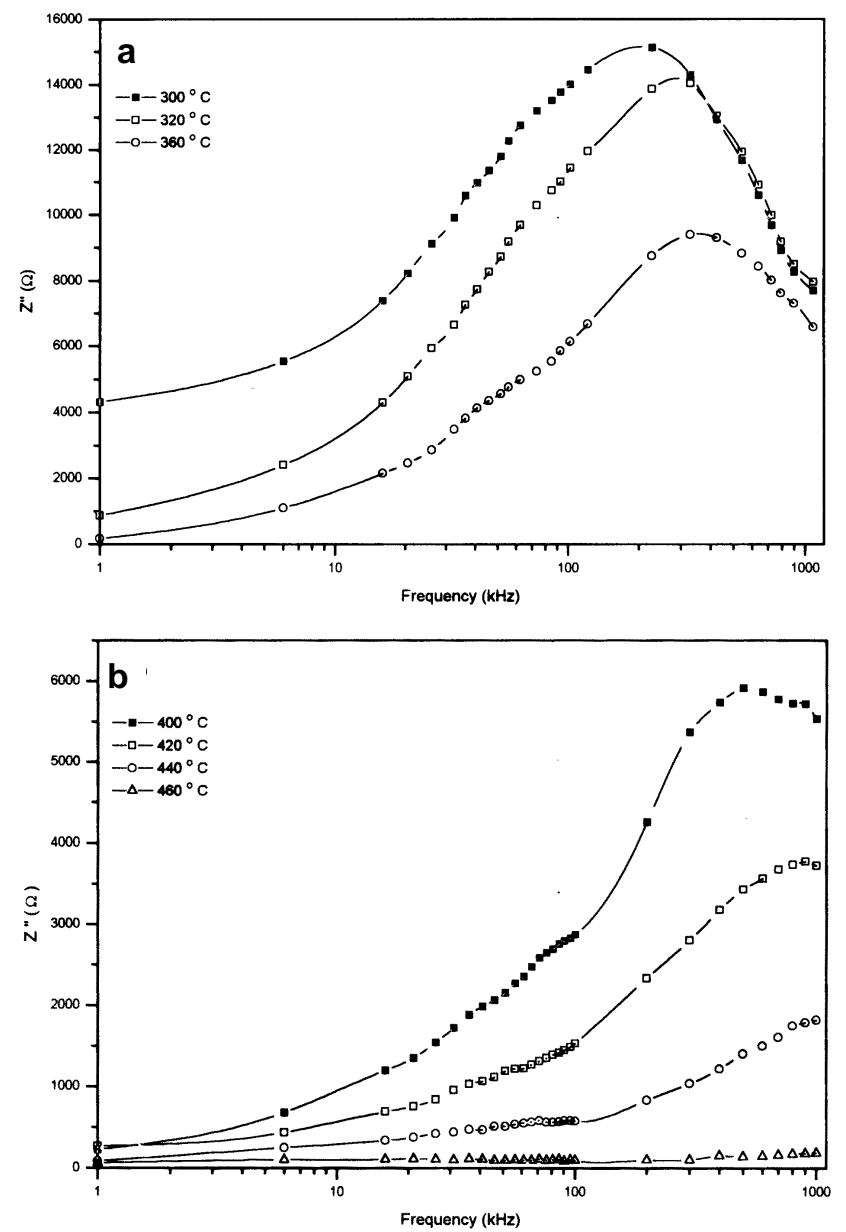

Figure 3. a-b. Variation of imaginary part of impedance as a function of frequency at temperature indicated for sintered DBFT. 
samples have higher density and probably better grain orientation, hence HIPed have lower relaxation frequencies and larger relaxation times as observed in the present work (figures $4 \mathrm{a}$ and $\mathrm{b}$ ). The relaxation times of HIPed DBFT are at least one order larger than those of sample A. The relaxation times considered here are the overall relaxation times depicting the average of all processes under way in the sample due to the application of a.c. fields.

When the continuously distributed activated energies are observed for different relaxational processes (Bunget and Popescu 1984) then,

$$
\tau=\tau_{0} \exp (E / k T)
$$

A plot of $\log \tau$ vs $1000 / T$ would be a straight line and the slope gives the average activation energy for relaxation of dipoles. The average values of such activation energies are found to be $0.46 \mathrm{eV}$ for sample $\mathrm{A}$ and $0.55 \mathrm{eV}$ for sample B.
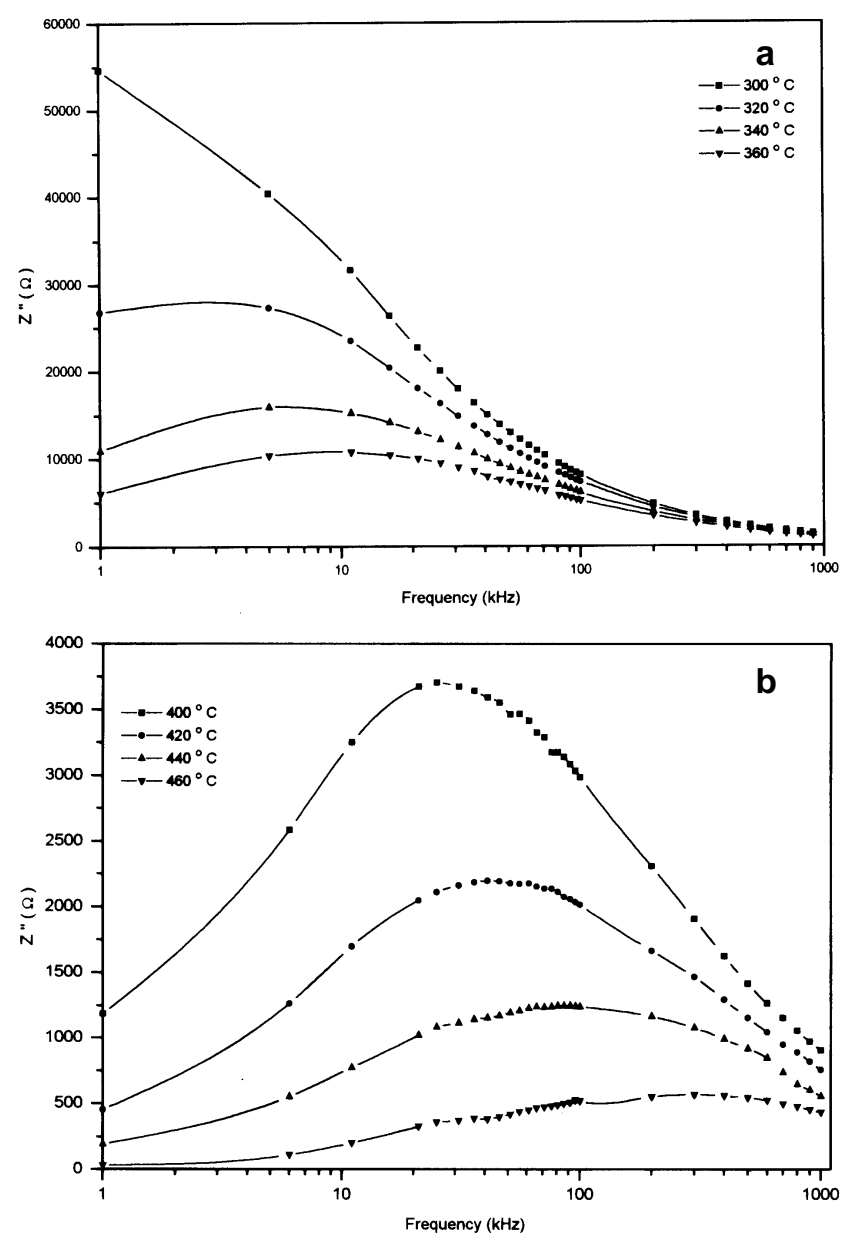

Figure 4. a-b. Variation of imaginary part of impedance as a function of frequency at the temperature indicated for sintered plus HIPed DBFT.
The complex impedance plots (figures 5a and b) at different temperatures enable the separation of intergranular from bulk phenomenon (MacDonald 1987). At lower temperatures, the d.c. conductivity is negligible and one can observe relaxation effects in the presence of a.c. fields. The former is due to long-range effects and the latter phenomenon is due to local defect relaxation. The impedance curves beyond a certain temperature would be semicircle. Each semicircle describes relaxation of a particular class of charge entity. Since the electrode effects are small in present measurements, the two semicircles observed in the present study can be attributed to grain and grain boundary effects. Each of these contributions can be represented by parallel or series combination of RC elements. The resistance value of each element can be found from the intercept of the arc on the real axis towards low frequency side. Lower frequency arcs are due to grain boundaries and higher frequency arcs depict grain effects. Within the bulk of the material, there are two possible a.c. conduction mechanisms: first the long range a.c. conductivity and the other local transport of oxygen vacancies. The long-range conduction by vacancies and by the way of charge compensation follows the equation (Prasad et al 1998).

$$
\mathrm{O}_{2}=1 / 2 \mathrm{O}_{2}+V_{0}^{\prime \prime}+2 e^{-}
$$

The oxygen vacancies are created due to the loss of oxygen by the material under study during sintering.

At low enough temperatures (and frequencies) the defects and charge complexes present in the sample associate giving rise to observed dielectric loss peaks due to their bound motion among all equivalent sites. The contribution to the long-range conductivity at low enough temperatures would be small and can be ignored. The long-range conductivity effects will be observable at higher temperatures. At these temperatures charge complexes may become unassociated and charges become mobile.

Grain and grain boundary resistances $\left(r_{\mathrm{g}}, r_{\mathrm{gb}}\right)$ and relaxation times $\left(\tau_{\mathrm{g}}, \tau_{\mathrm{gb}}\right.$, where $\tau=1 / \omega, \omega$ is frequency at maximum arc) are functions of temperature (Bunget and Popescu 1984). When $\log \tau$ is plotted as a function of inverse temperature a linear plot would result. Activation energies for conduction and relaxations within the grain $\left(E_{\mathrm{g}}, \varepsilon_{\mathrm{g}}\right)$ and grain boundary $\left(E_{\mathrm{gb}}, \varepsilon_{\mathrm{gb}}\right)$ are evaluated (table 2 ). The activation energies for relaxation within the grain and grain boundary in sample A are smaller than those in sample B. Grain and grain boundary conduction activation energy is larger in sample A. Observed differences in the activation energies of conduction and relaxation of grain and grain boundary may be due to the grain orientation in sample B. These observations are consistent with relaxations observed in $Z^{\prime \prime}$ versus frequency curves.

The impedance plots of DBFT are obtained with one semicircle for temperatures below $300^{\circ} \mathrm{C}$ representing 
bulk behaviour only. However, when the temperature is raised above $400^{\circ} \mathrm{C}$, the semicircle representing the grain boundary effect becomes visible at lower frequencies. For HIPed DBFT, separation of grain boundary effects are visible only above $400^{\circ} \mathrm{C}$. Observation of only two semi- circles over the entire range of temperature indicates negligible interfacial and electrode processes in the present system. Figures 6 and 7 show variation of real part of a.c. conductivity of samples $\mathrm{A}$ and $\mathrm{B}$ at different frequencies. At lower temperatures there is a frequency variation of
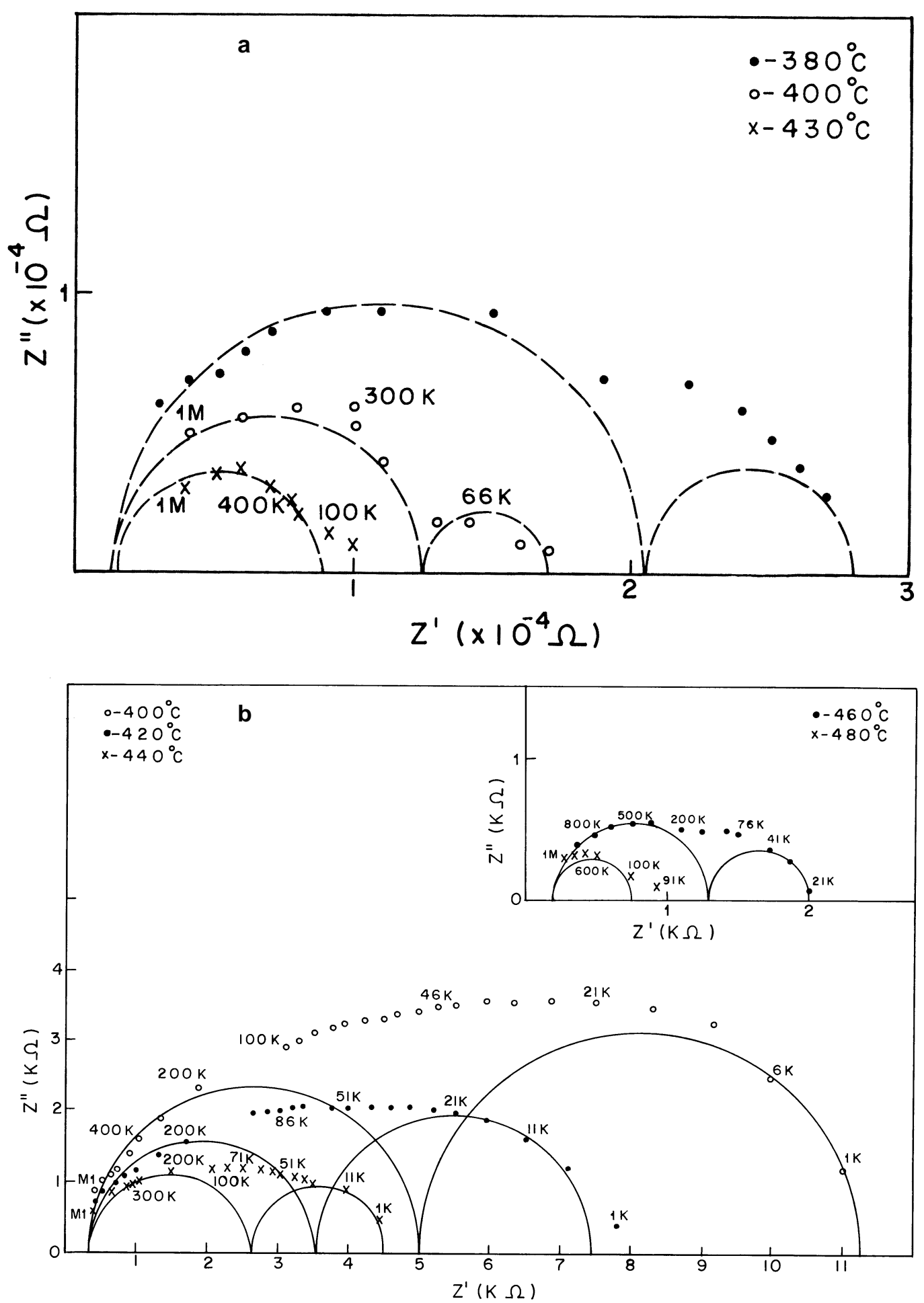

Figure 5. a. Variation of $Z^{\prime \prime}$ with $Z^{\prime}$ at different temperatures for sintered DBFT and b. variation of $Z^{\prime \prime}$ with $Z^{\prime}$ at different temperatures for sintered plus HIPed DBFT. 


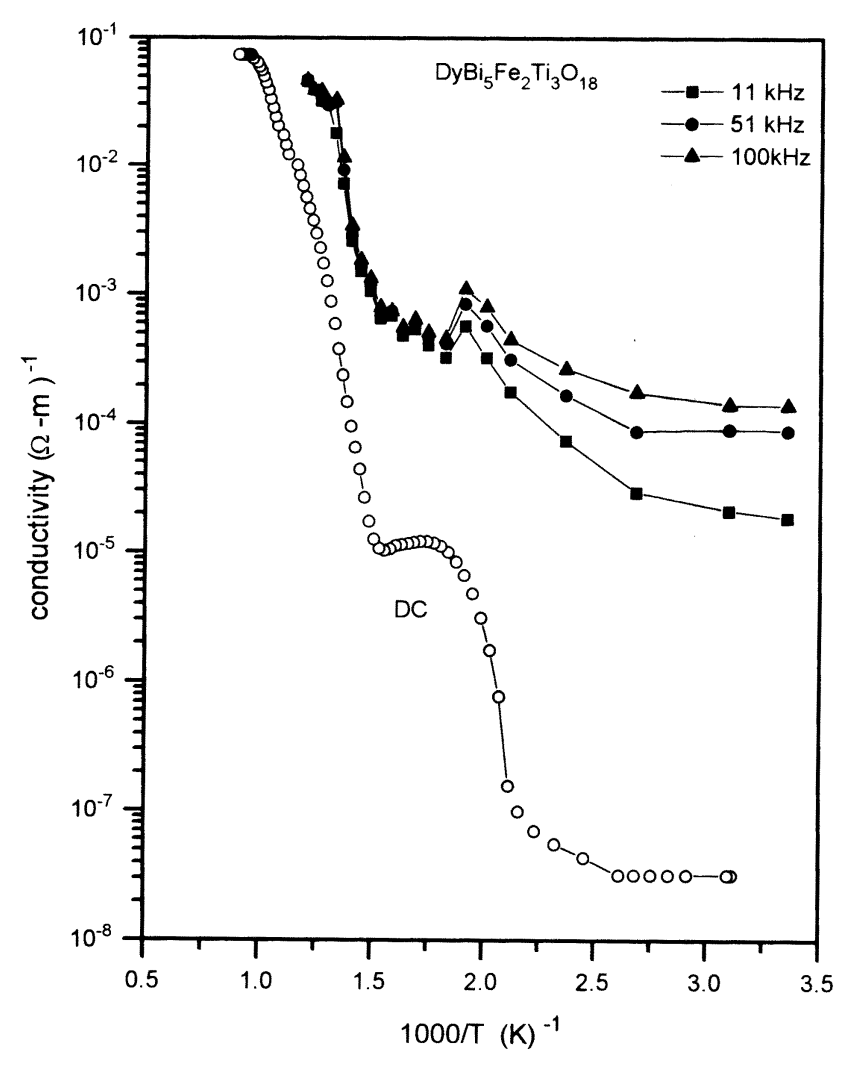

Figure 6. D.c. and a.c. conductivity as a function of inverse temperatures for sintered DBFT.

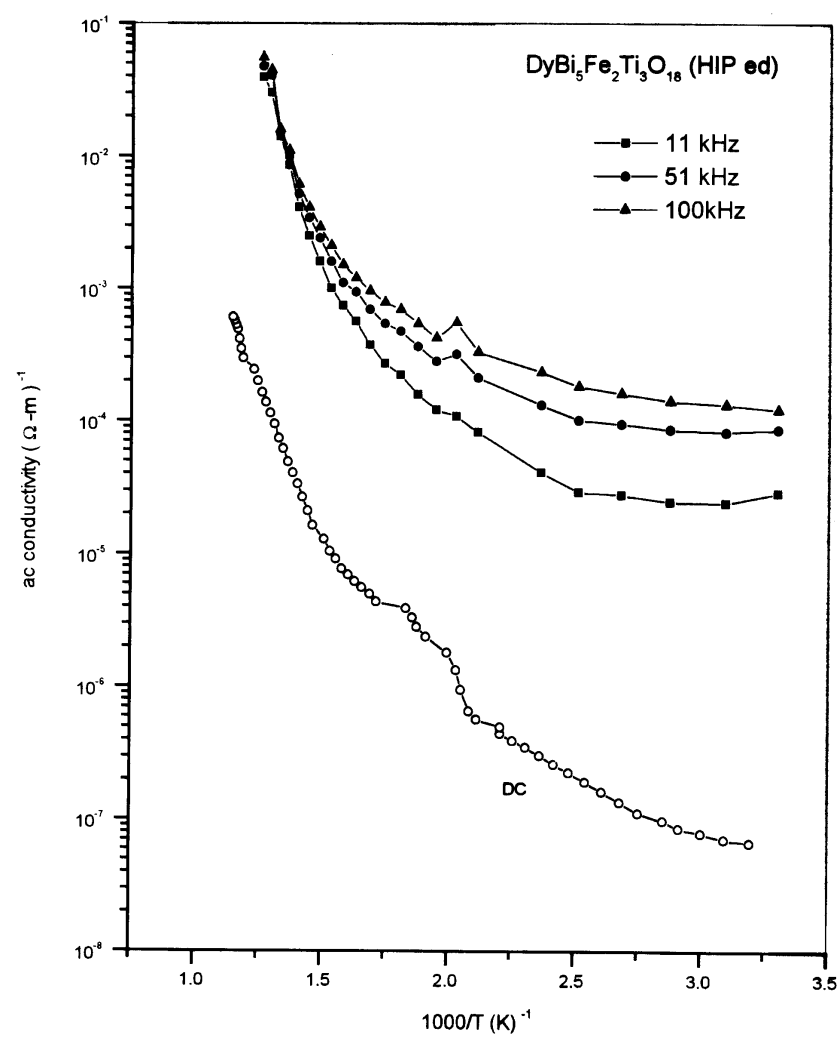

Figure 7. D.c. and a.c. conductivity as a function of inverse temperature for sintered plus HIPed DBFT. conductivity but at higher temperatures all the conductivity curves at different frequencies merge into one indicating intrinsic conductivity. Sintered sample showed a kink around $350^{\circ} \mathrm{C}$, at which a broad hump was observed in the variation of dielectric constant with temperature.

In both the samples (A and B) it is observed that the a.c. conductivity is higher than the d.c. conductivity. The admittance could not be measured at high temperatures, as the conductivity was higher than the range allowed in the impedance analyzer. The a.c. conductivity in the case of sample A shows a peak in the same temperature region at which peak was observed in the d.c. conductivity. However in sample B such peak was not observed, except at $100 \mathrm{kHz}$ frequency. Activation energies have been evaluated and are tabulated in tables $3 \mathrm{a}$ and $\mathrm{b}$ for both samples A and B. Unlike in case of d.c. conductivity, where a marked difference was observed in the variation in the two samples, the variation appears to be almost similar. This indicates that the relaxation mechanism has not been affected much because of HIPing.

It is known that the conductivity of a given sample is due to contribution from both free charge carrier motion and relaxation of dipoles. The first part of the conducti-

Table 2. Activation energies (eV) for conduction $(E)$ and relaxation $(\varepsilon)$ for grain $(\mathrm{g})$ and grain boundary $(\mathrm{gb})$ in the temperature region $300-420^{\circ} \mathrm{C}$.

\begin{tabular}{lcccc}
\hline Sample & $\begin{array}{c}E_{\mathrm{g}} \\
(\mathrm{eV})\end{array}$ & $\begin{array}{c}E_{\mathrm{gb}} \\
(\mathrm{eV})\end{array}$ & $\begin{array}{c}\varepsilon_{\mathrm{g}} \\
(\mathrm{eV})\end{array}$ & $\begin{array}{c}\varepsilon_{\mathrm{gb}} \\
(\mathrm{eV})\end{array}$ \\
\hline Sample A & 0.99 & 0.90 & 0.31 & 0.44 \\
Sample B & 0.73 & 0.87 & 1.23 & 0.61 \\
\hline
\end{tabular}

Table 3a. Activation energies $(\mathrm{eV})$ for conduction in the temperature ranges mentioned for sample A.

\begin{tabular}{|c|c|c|c|c|}
\hline \multirow{2}{*}{$\begin{array}{l}\text { Temp. } \\
\text { range }\left({ }^{\circ} \mathrm{C}\right)\end{array}$} & \multirow{2}{*}{$\begin{array}{l}\text { D.c. conductivity } \\
\text { activation energy } \\
\qquad(\mathrm{eV})\end{array}$} & \multicolumn{3}{|c|}{$\begin{array}{c}\text { A.c. conductivity } \\
\text { activation energies }(\mathrm{eV})\end{array}$} \\
\hline & & $11 \mathrm{kHz}$ & $51 \mathrm{kHz}$ & $100 \mathrm{kHz}$ \\
\hline $120-170$ & $0 \cdot 28$ & $0 \cdot 32$ & $0 \cdot 24$ & $0 \cdot 45$ \\
\hline $390-450$ & 1.49 & $0 \cdot 85$ & $0 \cdot 85$ & $0 \cdot 85$ \\
\hline $450-520$ & $2 \cdot 32$ & $2 \cdot 40$ & $2 \cdot 40$ & $2 \cdot 40$ \\
\hline
\end{tabular}

Table 3b. Activation energies (eV) for conduction in the temperature ranges mentioned for sample B.

\begin{tabular}{|c|c|c|c|c|}
\hline \multirow{2}{*}{$\begin{array}{l}\text { Temp. } \\
\text { range }\left({ }^{\circ} \mathrm{C}\right)\end{array}$} & \multirow{2}{*}{$\begin{array}{l}\text { D.c. conductivity } \\
\text { activation energy } \\
(\mathrm{eV})\end{array}$} & \multicolumn{3}{|c|}{$\begin{array}{c}\text { A.c. conductivity } \\
\text { activation energies }(\mathrm{eV})\end{array}$} \\
\hline & & $11 \mathrm{kHz}$ & $51 \mathrm{kHz}$ & $100 \mathrm{kHz}$ \\
\hline $120-170$ & $0 \cdot 69$ & $0 \cdot 19$ & $0 \cdot 19$ & $0 \cdot 22$ \\
\hline $320-390$ & 0.49 & 0.46 & $0 \cdot 29$ & $0 \cdot 38$ \\
\hline $390-520$ & 0.64 & 1.84 & 1.84 & 1.84 \\
\hline
\end{tabular}


vity is basically measured through d.c. conductivity, whereas the second part i.e. relaxation, is obtained from admittance of the sample measured as a function of frequency. In case of normal dielectric materials the conduction takes place through hopping between two ions of different valence states. In the present sample also there are cations with different valence states occupying both $\mathrm{A}$ and B sites. In addition to this, as mentioned earlier, the conduction mechanism is also through the migration of oxygen vacancies.

\section{Conclusions}

DyBi ${ }_{5} \mathrm{Fe}_{2} \mathrm{Ti}_{3} \mathrm{O}_{18}$ samples were prepared by solid state reaction method and also by HIPing technique (of the sintered samples) at $800^{\circ} \mathrm{C}$ by applying $100 \mathrm{MPa}$ pressure and then show appreciable changes in relaxation time, activation energy and conductivity values. This variation is attributed to densification of the sample leading to good contact between the grains and larger grain size.

\section{Acknowledgements}

One of the authors (NVP) thanks CSIR, New Delhi, for the award of a Senior Research Fellowship. We thank the referee for useful comments.

\section{References}

Aurivillius B 1949 Arki. Kemi 1 463, 499

Aurivillius B 1950 Arki. Kemi 219

Bunget I and Popescu M 1984 Physics of solid dielectrics (Elsevier Science)

Fregoso O A 1997 J. Appl. Phys. 811387

Gabbasova Z V, Kuz'min M D, Zvezdin A K, Dubenko I S, Murashov V A, Rukov D N and Krynetsky I B 1991 Phys. Lett. A158 491

Ismailzade I G, Nesterenko V I, Mirishili F A and Rustamov P A 1967 Sov. Phys. Crystallogr. 12400

James A R, Kumar G S, Suryanarayana S V and Bhimasankaram T 1998 Ferroelectrics 21611

MacDonald J R 1987 Impedance spectroscopy (NY: Wiley)

Prasad N V and Kumar G S 2000 J. Magn. \& Magn. Mater. 213 349

Prasad N V, Prasad G, Bhimasankaram T, Suryanarayana S V and Kumar G S 1998 Mod. Phys. Lett. B12 371

Subba Rao E C 1962 J. Phys. Chem. Solids 23665

Srinivas K and James A R 1999 J. Appl. Phys. 863885

Singh R S 1996 Structure-property correlations in some magnetically ordered Aurivillius phases, Ph.D. Thesis, Osmania University, Hyderabad

Suryanarayana S V 1994 Bull. Mater. Sci. 17259

Takenaka T and Sakata K 1980 Jap. J. Appl. Phys. 1931

White R L 1969 J. Appl. Phys. 401061 